Discussion Paper No. 797

\title{
MULTIMARKET LINKAGES, BUYER POWER, AND THE PRODUCTIVITY PUZZLE
}

\author{
Noriaki Matsushima
}

Laixun Zhao

October 2010

The Institute of Social and Economic Research

Osaka University

6-1 Mihogaoka, Ibaraki, Osaka 567-0047, Japan 


\title{
Multimarket Linkages, Buyer Power, and the Productivity Puzzle
}

\author{
Noriaki Matsushima* \\ Institute of Social and Economic Research, Osaka University \\ Laixun Zhao \\ Research Institute of Economics and Business, Kobe University
}

October 12,2010

\begin{abstract}
This paper examines the relationship between firms' productivity improvement and the volume of exports, and shows that it can be sometimes negative. Specifically, we simultaneously take into account intermediate retailers (i.e., vertically) and multimarket linkages (i.e., horizontally). We find that an improvement of the manufacturing productivity affects the bargained wholesale prices in opposite directions in asymmetric markets, causing retailers to make corresponding changes that look surprising. This result can explain for the empirical "productivity puzzle" found in Ghemawat et al. (2010). Related to this issue is the relationship between buyer power (caused by a retail merger) and profitability. Contrary to the existing literature, in an extended setup, we find that the merger between the downstream duopolists does not improve their profits if their bargaining power is strong vs. upstream suppliers.
\end{abstract}

JEL Classification Codes: L12, L14, F12, F23

Key Words: Vertical Structure, Market power, Productivity, Multi-Market Bargaining.

\footnotetext{
*Corresponding author: Noriaki Matsushima, Institute of Social and Economic Research, Osaka University, Mihogaoka 6-1, Ibaraki, Osaka 567-0047, Japan. Phone: +81-6-6879-8571. Fax: +81-8-6879-8583. E-mail: nmatsush@iser.osakau.ac.jp
} 


\section{Introduction}

A recent paper by Ghemawat et al. (2010) poses an interesting "productivity puzzle": there is "an apparent lack of any relationship" between productivity growth rates in Catalan manufacturing and changes in international trade position. This finding seems to be inconsistent with the standard results in the international trade literature. ${ }^{1}$ However, they also point out that replacing international trade with both interregional and international trade seems to take care of this puzzle; that is, there is a positive correlation between productivity growth rates and changes in interregional and international trade position.

The present paper is motivated by their empirical finding. We ask the following question: does productivity improvement always enhance exports? Our theoretical model shows that the answer is sometimes "no." Specifically, we take into account intermediate retailers and multimarket linkages which have not been considered in the existing literature dealing with productivity and exports. We find that a productivity improvement affects the bargained wholesale prices in opposite directions in markets that are asymmetric, causing retailers to make corresponding changes that look surprising. Our setup is natural because many final product makers do not directly sell to consumers but sell through retailers. For instance, automobile manufacturers contract with car dealers, and consumer-electronics makers supply to retailers, who then sell to consumers.

The detailed basic model is as follows. Consider two independent downstream markets, one of which is "domestic" and the other "foreign." To closely follow Ghemawat et al. (2010), the latter market (foreign market) is assumed to be bigger than the former one (Spanish market). In each market, there is a monopolistic retailer that sells an identical product, which is produced by a common upstream manufacturer. Retailers incur no additional costs except the wholesale price which is bargained between the retailer and the manufacturer. Parallel trading is prohibitively costly. The manufacturer's marginal production cost is increasing in total output.

We find a non-monotone relationship between a manufacturer's productivity improvement and its

\footnotetext{
${ }^{1}$ On the relationship between productivity and exports, recent theoretical papers include for instance Melitz (2003) and Melitz and Ottaviano (2008), and for recent empirical studies, please see Bernard and Jensen (1995, 1999), Bernard et al. (2003), and Helpman et al. (2004). Wagner (2007) provides an excellent survey on this topic.
} 
volume of exports, even though there exists a monotonically positive relationship between the manufacturer's productivity improvement and its volume of total production. ${ }^{2}$ The key lies in the two simultaneous bargaining games for the wholesale prices. An efficiency improvement also raises the manufacturer's outside options, and the outside option of the bigger market (i.e., the profit from the smaller market) is raised more, which enables it to obtain a higher wholesale price in the bigger market. As a consequence, the retailer in this market buys less. This result can probably explain for the puzzle found in Ghemawat et al. (2010), and it highlights the importance of taking into account the vertical relationship between the manufacturer and retailers, as well as their strategic interactions through which profit shifting is carried out across multimarkets horizontally. ${ }^{3}$

We then extend the model to examine (i) the robustness of the results in the basic model and (ii) the relationship between buyer power and profitability. By incorpotating direct downstream competition, we first show that the "productivity puzzle" still holds in the extended setting, then we examine how the buyer power caused by a downstream merger affects the social surplus and the profitability of the merged firm. We find that the horizontal merger is unprofitable if the bargaining power of the merged firm is strong, which is starkly different from that in the literature, for instance, Lommerud et al. (2005) and Symeonidis (2010), who show that the horizontal merger is unprofitable if the bargaining power of the merged firm is weak. We also find that the merger improves welfare if the bargaining power of the upstream suppliers is weak.

In the literature, Horn and Wolinsky (1988), Dobson (1994), Zhao (2001) and Marshall and Merlo (2004) also adopt simultaneous bargaining structures. However, the main concerns of these studies are bargaining procedures among the labor union and final-product firms. They do not consider the relationship between productivity and exports, and there are no intermediate traders in these studies.

Our model setting is closely related to Inderst and Wey (2007), who assume $n$ downstream firms located in $n$ independent markets. The firms procure inputs from a single supplier with a convex production function. They show that a larger buyer can get a discount, which is higher the larger his

\footnotetext{
2 The result holds even when there is more than one manufacturer.

${ }^{3}$ Rey and Tirole (2007) and Inderst (2010) include surveys of recent progress on the study of vertical relations.
} 
share of the supplier's business. Moreover, the supplier is strictly worse off after the creation of a larger buyer through a merger. ${ }^{4}$ However, our concerns are on merger and buyer power. Their interactions under multimarket linkages generate results that complement Inderst and Wey (2007) in important ways.

The remainder of this paper is organized as follows. Section 2 formulates the basic model. Section 3 presents the main results and also extends the basic model. And Section 4 includes concluding remarks. Detailed calculations are delegated to the Appendix.

\section{The Model}

Consider two independent downstream markets in two countries. In each market, there is a monopolistic retailer ( $D$ in one country and $F$ in the other country) that sells an identical product, which is produced by a common upstream manufacturer $M$. In each downstream market, the demand for the product is linear:

$$
p_{i}=a_{i}-Q_{i},
$$

where $a_{i}$ is a positive constant, $p_{i}$ is the market price, $Q_{i}$ is the output supplied by retailer $i(i=D, F)$. To simplify the analysis, we assume that $a_{D}=1$ and $a_{F}>1$, i.e., the market of retailer $F$ is larger than that of retailer $D$. In the basic model we assume the two markets are segmented, and parallel trading is not allowed. These restrictions will be relaxed later.

The production technology of manufacturer $M$ is denoted by:

$$
C\left(Q_{D}, Q_{F}\right)=c\left(Q_{D}+Q_{F}\right)^{2}
$$

where $c$ is a positive constant. Retailers incur no additional costs except for the wholesale price, $w_{i}$ $(i=D, F)$, which is bargained between the retailer and the manufacturer. The market structure in this model is summarized by Figure 1 .

\section{[Figure 1 here]}

\footnotetext{
4 In a similar vein, Inderst and Valletti (2009) consider a case in which a large buyer controls several downstream firms in separate markets. This buyer's wholesale price is then strictly smaller than the wholesale price in the case of symmetric buyers, which is in turn lower than the wholesale price of competing smaller firms. Eső et al. (2010) consider a downstream industry where firms compete to buy capacity in an upstream market which allocates capacity efficiently.
} 
The wholesale prices $w_{D}$ and $w_{F}$ are determined by Nash bargaining. We have in mind two simultaneous bargaining games: the manufacturer negotiates simultaneously but independently with the two downstream retailers. Bargaining occurs before actual production takes place. Given $w_{j}(i, j=D, F$, $j \neq i$ ), the bargaining problem between manufacturer $M$ and retailer $i$ is described by the payoff pairs $B_{i}^{I} \equiv\left\{\left[\left(w_{i} Q_{i}+w_{j} Q_{j}\right)-C\left(Q_{i}, Q_{j}\right), \pi_{i}\right] \mid w_{i} \geq 0\right\}$ and the disagreement point $\left(w_{j} Q_{j}-C\left(0, Q_{j}\right), 0\right)$, where $\pi_{i}$ is the profit of retailer $i$ given by $\pi_{i}=\left(p_{i}-w_{i}\right) Q_{i}$.

The solution to the bargaining problem can be written as:

$$
w_{i}=\arg \max _{w_{i}} \beta \log \left[\pi_{i}\right]+(1-\beta) \log \left[\left(w_{i} Q_{i}+w_{j} Q_{j}\right)-C\left(Q_{i}, Q_{j}\right)-\left(w_{j} Q_{j}-C\left(0, Q_{j}\right)\right)\right]
$$

where $\beta \in[0,1]$ measures the bargaining power of retailer $i$ relative to that of manufacturer $M .^{5}$

We consider a game sequence as follows. First, the manufacturer and the retailers negotiate the wholesale prices $w_{i}(i=D, F)$. Second, given the wholesale prices, each retailer sets its quantity supplied to consumers. The game is solved by backward induction. ${ }^{6}$

\section{The Basic Results}

Given the negotiated wholesale price $w_{i}$, the maximization problem of retailer $i(i=D, F)$ is

$$
\max _{Q_{i}} \pi_{i}=\left(a_{i}-Q_{i}-w_{i}\right) Q_{i}
$$

The first-order conditions lead to (Second order conditions are satisfied)

$$
Q_{i}=\frac{a_{i}-w_{i}}{2}, \quad \pi_{i}=\frac{\left(a_{i}-w_{i}\right)^{2}}{4}
$$

\footnotetext{
5 This bargaining structure is often used in the literature of industrial organization. An important property of the Nash bargaining solution is that it can be implemented as the outcome of a dynamic non-cooperative alternating-offers bargaining game (Rubinstein, 1982 and Binmore et al., 1986).

${ }^{6}$ We do not consider non-linear contracts. As documented in Iyer and Villas-Boas (2003, p.81), in practice, both the magnitude and the incidence of two-part tariffs may be insignificant. The fee structure employed here is different from that in Inderst and Wey (2007), where each trading partner uses a lump-sum transfer. This difference in fee structures leads to quite different results.
} 
Substituting (2) into (1), we can rewrite the negotiated wholesale prices as

$$
\begin{aligned}
w_{D}= & \arg \max _{w_{D}} \beta \log \left[\frac{\left(1-w_{D}\right)^{2}}{4}\right] \\
& +(1-\beta) \log \left[\frac{w_{D}\left(1-w_{D}\right)}{2}-c\left(\frac{1-w_{D}}{2}+\frac{a_{F}-w_{F}}{2}\right)^{2}+c\left(\frac{a-w_{F}}{2}\right)^{2}\right], \\
w_{F}= & \arg \max _{w_{F}} \beta \log \left[\frac{\left(a_{F}-w_{F}\right)^{2}}{4}\right] \\
& +(1-\beta) \log \left[\frac{w_{F}\left(a_{F}-w_{F}\right)}{2}-c\left(\frac{1-w_{D}}{2}+\frac{a_{F}-w_{F}}{2}\right)^{2}+c\left(\frac{1-w_{D}}{2}\right)^{2}\right] .
\end{aligned}
$$

These lead to the following reaction functions:

$$
\begin{aligned}
& w_{D}=\frac{1-\beta+\left(1+a_{F}(1+\beta)\right) c-(1+\beta) c w_{F}}{2+c}, \\
& w_{F}=\frac{(1-\beta) a_{F}+\left(1+a_{F}+\beta\right) c-(1+\beta) c w_{D}}{2+c} .
\end{aligned}
$$

From the above, we obtain the following lemma:

Lemma 1 (Pricing Strategy): For any $c(>0)$, the wholesale prices are strategic substitutes, and the degree of strategic substitutability increases in c.

This Lemma arises because the reaction functions become steeper as the value of $c$ increases (see Figure 2).

[Figure 2 here]

Lemma 1 says that when $w_{i}$ is low, $w_{j}$ must be high. This stems from the two bargaining games. The downstream retailers "indirectly" compete with each other through their independent but simultaneous negotiations with the upstream manufacturer. This strategic substitutability does not depend on the linearity of the demand functions. In the Appendix, we show that this relationship holds under general conditions.

We now use this insight to examine how $c$ affects $w_{i}$ and $Q_{i}(i=D, F)$. A higher $c$ implies a higher and faster-rising marginal cost. Then it becomes increasingly difficult for the manufacturer to produce a larger quantity. In turn, competition between the retailers for the manufacturer's product becomes more fierce, shown by the increasing slopes of the reaction curves as $c$ rises in Figure 2 . 
Next, the wholesale prices and quantities in equilibrium can be straightforwardly calculated as, for all $i, j=D, F ; i \neq j$

$$
\begin{aligned}
w_{i} & =\frac{2(1-\beta) a_{i}+\left((3-\beta) a_{i}+(1+\beta)^{2} a_{j}\right) c-a_{i} \beta(2+\beta) c^{2}}{(2-c \beta)(2+(2+\beta) c)}, \\
Q_{i} & =\frac{(1+\beta)\left(2 a_{i}-\left((1+\beta) a_{j}-a_{i}\right) c\right)}{2(2-c \beta)(2+(2+\beta) c)} .
\end{aligned}
$$

The difference between $w_{D}$ and $w_{F}$ and its partial derivative with respect to $c$ are respectively

$$
w_{D}-w_{F}=\frac{\left(a_{F}-1\right)(\beta c-(1-\beta))}{(2-c \beta)}, \quad \frac{\partial\left(w_{D}-w_{F}\right)}{\partial c}=\frac{\left(a_{F}-1\right) \beta(1+\beta)}{(2-c \beta)^{2}} \geq 0
$$

Note we have assumed $a_{F}>1$.

From Lemma 1, when $c$ becomes higher, not only competition is intensified, but also the procurement condition of the foreign retailer becomes better than that of the domestic retailer, due to the former's larger market size. This enables the foreign retailer to supply more final output than the domestic retailer. In fact, we have

Lemma 2 When c is sufficiently large, the manufacturer supplies only to the foreign retailer.

In Lemma 2, $c$ affects the manufacturer's decision as follows. In the two bargaining games, the manufacturer's threat-point payoff is higher when negotiating with retailer $D$ than with $F$, since if the former (latter) negotiation broke down, the remaining market for the manufacturer is large (small). And as $c$ increases, the difference between the threat-point payoffs becomes larger (see the last terms in (3) and (4)). The quantities supplied in the two markets (see (8)) show that the foreign retailer wins this intensified competition, due to its larger market.

We now look into how the quantity supplied in each market changes with an increase in $c$. Differentiation yields

$$
\begin{aligned}
\frac{\partial\left(Q_{F}+Q_{D}\right)}{\partial c} & =-\frac{\left(1+a_{F}\right)(1+\beta)(2+\beta)}{2(2+(2+\beta) c)^{2}}<0 \\
\frac{\partial Q_{D}}{\partial c} & =-\frac{(1+\beta) K}{2(2-c \beta)^{2}(2+(2+\beta) c)^{2}}<0 \\
\frac{\partial Q_{F}}{\partial c} & =\frac{\beta(2+\beta)\left[4 a_{F}-\left(1+\beta-a_{F}\right) c\right] c-4\left(1+a_{F}+\beta\right)}{2(2-c \beta)^{2}(2+(2+\beta) c)^{2}} .
\end{aligned}
$$


Both the domestic quantity and the world total quantity decrease as $c$ increases, ${ }^{7}$ which is as expected. However, foreign sales may decrease or increase. We find $\partial Q_{F} / \partial c>0$ if and only if $c>c_{F}$, where

$$
c_{F} \equiv \begin{cases}\frac{2\left[a_{F} \beta(2+\beta)-(1+\beta) \sqrt{\left(a_{F}^{2}-1\right) \beta(2+\beta)}\right]}{\beta(2+\beta)\left(1+\beta-a_{F}\right)} & \text { if } a_{F} \neq 1+\beta, \\ \frac{2}{\beta(2+\beta)} & \text { if } a_{F}=1+\beta .\end{cases}
$$

Note that we must also take into account the boundary condition. Using $Q_{D}$ in (8), we find that $Q_{D}>0$ if and only if

$$
c<\bar{c} \equiv \frac{2}{(1+\beta) a_{F}-1} .
$$

The relation between $c_{F}$ and $\bar{c}$ is as follows:

Lemma $3 c_{F}<\bar{c}$ if and only if $1<a_{F}<1+\beta$.

From the above, we obtain the following proposition (see alsoFigure 3).

Proposition $1 Q_{F}$ is increasing in $c$ if $c_{F}<c<\bar{c}$ and $1<a_{F}<1+\beta$.

[Figure 3 here]

Intuitively, Proposition 1 can be understood as follows. Consider a decrease in $c$, which increases the total quantity supplied by the manufacturer $Q_{D}+Q_{F}$. However, the composition of it, $Q_{D}$ and $Q_{F}$, is also affected (see Figure 4). And how the composition changes depends on the strategic substitutability of the two wholesale prices determined in the bargaining games. By Lemma 1, an increase in $Q_{D}$ (i.e., a decrease in $w_{D}$ ) has a negative impact on $Q_{F}$. When $c$ is large, the degree of strategic substitutability is high, and the resulted sales substitution between the two retailers is also large. As a result, a decrease in $c$ can reduce $Q_{F}$ when $c$ is large.

\footnotetext{
${ }^{7}$ In the equation for $\partial Q_{D} / \partial c$,

$$
K \equiv 4\left(1+(1+\beta) a_{F}\right)-4 \beta(2+\beta) c+\beta(2+\beta)\left(a_{F}(1+\beta)-1\right) c^{2}
$$

We can easily show that $K$ is minimized when $c=2 /\left((1+\beta) a_{F}-1\right)$, and the minimized value is

$$
K_{\min }=\frac{4\left(a_{F}^{2}-1\right)(1+\beta)^{2}}{(1+\beta) a_{F}-1}>0 .
$$
}

Therefore, for any $c, \partial Q_{D} / \partial c$ is negative. 
[Figure 4 here]

This proposition can perhaps explain the stylized fact that in some markets, the volume of exports may fall as a firm's production efficiency improves (Ghemawat et al., 2010). It highlights the importance of taking into account the vertical relationship between the manufacturer and retailers and their strategic interactions through which profit shifting is carried out across multimarkets.

Remark 1 The Choice of Retailers It has been assumed that the manufacturer must negotiate with both retailers. We can also consider the case in which it chooses to deal with only one or both retailers. Suppose only one retailer is chosen, then it must be foreign because the foreign market is larger than the domestic one. In the revised setting, the game becomes a three-stage game. First, the manufacturer determines the number of trading partners. Second, it negotiates with the retailers independently and simultaneously. Finally, given the wholesale prices, each retailer determines its retail price. We can straightforwardly show that for any $c<\bar{c}$, the manufacturer always decides to trade with both retailers simultaneously.

Remark 2 The Necessity of both Retailers The existence of the retailers in two simultaneous bargaining games is essential to derive our main results. When the manufacturer directly supplies to consumers instead, the quantity supplied in each market monotonically increases with the efficiency improvement (the decrease in c). ${ }^{8}$ Intuitively, without the retailers, the monopolist can increase production at its discretion when its efficiency is improved. However, under two simultaneous bargaining games, an efficiency improvement also raises the manufacturer's outside options. Specifically, the outside option of the bigger domestic market is raised more, which enables it to obtain a higher wholesale price, as shown in (9) and Lemma 2. As a consequence, the retailer in this (foreign) market buys less.

Remark 3 Parallel Trade One might wonder what would happen if parallel trading is allowed. We find that it does not matter much when the market-size difference is small. That is, our main results hold even when we incorporate parallel traders into the model.

\footnotetext{
8 The detail of this discussion is upon request.
} 


\section{Separate Downstream Duopolists}

So far we have considered only one manufacturer. Now we extend the basic model to examine the cases where retailers coexist in each market. There are still two retailers, but in case (i), the retailers are independent of each other in both the domestic and foreign markets; and in case (ii), the retailers are independent in one market but merged in the other market.

The first case enables us to check the robustness of Proposition 1, and we find that the additional retailers and manufacturers do not affect the result that the volume of exports may fall as firms' production efficiency is improved (Ghemawat et al., 2010).

With the second case, we investigate the effects of retail merger and how the merged large retailer influences market performance. The problem caused by large retailers is an important topic in the context of industrial organization (see for instance, Inderst and Shaffer, 2007). ${ }^{9}$ Some large retailers (e.g, Tesco in the UK and Metro in Germany) can exert countervailing powers against upstream suppliers. Such powers on the one hand reduce wholesale prices which may increase welfare, but on the other hand they exert market power on final consumers which tends to lower welfare.

For our purpose, the simplest setup is as follows. In each market, a retailer procures from manufacturer $A$ and the other from manufacturer $B$. Neither retailer procures from both manufacturers, nor do both retailers procure from the same manufacturer. For details, please see Figure 5.

[Figure 5 here]

The assumptions concerning the manufacturers are similar to those in the previous section. With two manufacturers $j \in\{A, B\}$, their cost functions are also different as follows,

$$
C_{j}\left(Q_{i, j}, Q_{-i, j}\right)=c_{j}\left(Q_{i, j}+Q_{-i, j}\right)^{2}
$$

where $Q_{i, j}$ is the output of 'retailer $i, j$ '. We denote 'retailer $i, j$ ' a retailer in market $i \in\{D, F\}$ who procures from manufacturer $j \in\{A, B\}$. Assuming the bargaining power of each retailer in market $i$ to

\footnotetext{
9 Inderst and Shaffer (2007) analyze the impact of retail mergers on product variety. They show that, following a merger, a retailer may want to enhance its buyer power by committing to a 'single-sourcing' purchasing strategy.
} 
be given as $\beta_{i} \in(0,1)(i \in\{D, F\})$, we can write the solution to the bargaining problem as:

$$
\begin{aligned}
w_{i, j}=\arg \max _{w_{i, j}} \beta_{i} \log \left[\pi_{i, j}\right]+ & \\
& \left(1-\beta_{i}\right) \log \left[\left(w_{i, j} Q_{i, j}+w_{-i, j} Q_{-i, j}\right)-C_{j}\left(Q_{i, j}, Q_{-i, j}\right)-\left(w_{-i, j} Q_{-i, j}-C_{j}\left(0, Q_{-i, j}\right)\right)\right],
\end{aligned}
$$

where $\pi_{i, j}$ is the profit, $w_{i, j}$ is the wholesale price, and $Q_{i, j}$ is the output, all related to retailer $i, j$.

In market $i \in\{D, F\}$, the inverse demand is given as:

$$
p_{i, j}=a_{i}-Q_{i, j}-\gamma Q_{i,-j}
$$

where $a_{i}$ is a positive constant, $p_{i, j}$ is the market price for product $j$, and $\gamma \in(0,1)$ is the degree of product differentiation between the two products.

\subsection{Downstream duopoly}

We first consider the case of the retailers being independent of each other in both the domestic and foreign markets. Given the negotiated wholesale price $w_{i, j}$, the maximization problem of retailer $i, j$ $(i=D, F, j=A, B)$ is

$$
\max _{Q_{i, j}} \pi_{i}=\left(a_{i}-Q_{i, j}-\gamma Q_{i,-j}-w_{i, j}\right) Q_{i, j} .
$$

The first-order conditions lead to (second order conditions are satisfied)

$$
Q_{i, j}=\frac{(2-\gamma) a_{i}-2 w_{i, j}+\gamma w_{i,-j}}{4-\gamma^{2}}, \quad \pi_{i, j}=\left(Q_{i, j}\right)^{2} .
$$

Substituting (15) into (14), we can rewrite the negotiated wholesale prices as

$$
\begin{aligned}
& w_{i, j}=\arg \max _{w_{i, j}} \beta_{i} \log {\left[\frac{\left((2-\gamma) a_{i}-2 w_{i, j}+\gamma w_{i,-j}\right)^{2}}{\left(4-\gamma^{2}\right)^{2}}\right] } \\
&+\left(1-\beta_{i}\right) \log \left[\frac{w_{i, j}\left((2-\gamma) a_{i}-2 w_{i, j}+\gamma w_{i,-j}\right)}{4-\gamma^{2}}\right. \\
&-c\left(\frac{(2-\gamma) a_{i}-2 w_{i, j}+\gamma w_{i,-j}}{4-\gamma^{2}}+\frac{(2-\gamma) a_{-i}-2 w_{-i, j}+\gamma w_{-i,-j}}{4-\gamma^{2}}\right)^{2} \\
&\left.+c\left(\frac{(2-\gamma) a_{-i}-2 w_{-i, j}+\gamma w_{-i,-j}}{4-\gamma^{2}}\right)^{2}\right]
\end{aligned}
$$

These yield the following reaction functions $(i \in\{D, F\}, j \in\{A, B\})$ :

$$
\begin{aligned}
w_{i, j}=\frac{1}{4\left(4-\gamma^{2}+2 c_{j}\right)} \times\left[(2-\gamma)\left(a_{i}\left(1-\beta_{i}\right)\left(4-\gamma^{2}\right)+4\left(a_{i}+\left(1+\beta_{i}\right) a_{-i}\right) c_{j}\right)\right. \\
\left.-4 c_{j}\left(1+\beta_{i}\right)\left(2 w_{-i, j}-\gamma w_{-i,-j}\right)+\gamma\left(\left(1-\beta_{i}\right)\left(4-\gamma^{2}\right)+4 c_{j}\right) w_{i,-j}\right] .
\end{aligned}
$$


Notice that there are three other wholesale prices on the RHS: $w_{i,-j}, w_{-i, j}$ and $w_{-i,-j}$, which represent respectively the wholesale prices for retailers $i,-j,-i, j$, and $-i,-j$. Retailer $i, j$ directly competes with retailer $i,-j$ in market $i$, indirectly competes with retailer $-i, j$ through manufacturer $j$, and is also indirectly related to retailer $-i,-j$ through manufacturer $j$. Let us now examine their respective relationships with $w_{i, j}$, which yields interesting comparisons.

Lemma 4 In the reaction function of $w_{i, j}$, the coefficients of $w_{i,-j}, w_{-i, j}$, and $w_{-i,-j}$ are respectively positive, negative, and positive.

The coefficient of $w_{i,-j}$ is positive, so that the wholesale prices are complements across retailers in market $i(i=D, F)$. That is, in each market, retailer $i, j$ 's wholesale price increases in retailer $i,-j$ 's wholesale price. These can be understood as follows. A higher wholesale price for retailer $i,-j$ increases its cost, giving a competitive edge to its rival retailer $i, j$, enabling the latter to supply more in the retail market. And anticipating retailer $i, j$ 's action, manufacturer $j$ bargains for a higher wholesale price, resulting in the positive coefficient of $w_{i,-j}$. Note that this effect diminishes as the retailer's bargaining power $\beta_{i}$ increases, because wholesale prices and profits will be depressed by a higher $\beta_{i}$, which in turn reduces the intensity of the strategic interaction between the upstream suppliers (this possibility is also mentioned in Naylor (2002)).

In contrast, the coefficient of $w_{-i, j}$ is negative. As explained in the previous section with one manufacturer, retailers $i, j$ and $-i, j$ indirectly compete with each other through manufacturer $j$. If retailer $-i, j$ procures more, the manufacturer must supply less to retailer $i, j$ because the marginal cost of the manufacturer rises by the increase in $Q_{-i, j}$, which forces up the wholesale price $w_{i, j}$. Note that this effect becomes stronger as the values of $\beta_{i}$ and $c$ increase. A high retailer bargaining power $\beta_{i}$ depresses the wholesale price, enabling the retailer to procure more. The increase in $Q_{i, j}$ through the increase in $\beta_{i}$ enhances the marginal impact of the increase in $Q_{-i, j}$ (the decrease in $w_{-i, j}$ ). A higher $c$ tightens the production 'capacity' of the manufacturer. Therefore, the absolute value of the coefficient of $w_{-i, j}$ increases as the values of $\beta_{i}$ and $c$ increase.

Further, the coefficient of $w_{-i,-j}$ is positive. The logic can be explained analogously as before. A higher $w_{-i,-j}$ increases the quantity supplied by manufacturer $j$ in market $-i$, which tends to reduce 
its supply to retailer $i, j$, again driving up the wholesale price $w_{i, j}$.

Using the reaction functions $w_{i, j}=w_{i, j}\left(w_{i,-j}, w_{-i, j}, w_{-i,-j}\right)$, we also obtain the following lemma:

Lemma 5 At the equilibrium, the wholesale price $w_{i, j}^{*}$, the quantity $Q_{i, j}$, each retailer's profit, and the consumer surplus in each market are respectively

$$
\begin{aligned}
w_{i, j}^{*}= & a_{i}+\frac{\left(a_{-i}-a_{i}\right)\left[\left(4-\gamma^{2}\right)\left(4\left(1+\beta_{i}\right)+\left(1+\beta_{-i}\right)\left(1-\beta_{i}\right) \gamma\right)-8 \beta_{-i}\left(1+\beta_{i}\right) c_{-j}-4 \gamma \beta_{i}\left(1+\beta_{-i}\right) c_{j}\right]}{H_{a}} \\
& -\frac{\left(a_{-i}+a_{i}\right)\left[\left(4-\gamma^{2}\right)\left(4\left(1+\beta_{i}\right)+\left(1+\beta_{-i}\right)\left(1-\beta_{i}\right) \gamma\right)\right.}{H_{b}}, \\
& -\frac{4\left(a_{-i}+a_{i}\right)\left[2\left(2+\beta_{-i}\right)\left(1+\beta_{i}\right) c_{-j}+\gamma\left(2+\beta_{i}\right)\left(1+\beta_{-i}\right) c_{j}\right]}{H_{b}}, \\
Q_{i, j}= & \frac{(2-\gamma) a_{i}-2 w_{i, j}^{*}+\gamma w_{i,-j}^{*}}{4-\gamma^{2}}, \quad \pi_{i, j}=\left(Q_{i, j}\right)^{2}, \quad C S_{i}=(1+\gamma)\left(Q_{i, j}\right)^{2} .
\end{aligned}
$$

where $H_{a} \equiv 16\left(2-\beta_{i} c_{j}\right)\left(2-\beta_{-i} c_{-j}\right)-4\left(5-\beta_{i}-\beta_{-i}+\beta_{i} \beta_{-i}-\beta_{i}\left(1-\beta_{-i}\right) c_{j}-\beta_{-i}\left(1-\beta_{i}\right) c_{-j}\right) \gamma^{2}+(1-$ $\left.\beta_{i}\right)\left(1-\beta_{-i}\right) \gamma^{4}$ and $H_{b} \equiv 16\left(2+\left(2+\beta_{i}\right) c_{j}\right)\left(2+\left(2+\beta_{-i}\right) c_{-j}\right)-4\left(5-\beta_{i}-\beta_{-i}+\beta_{i} \beta_{-i}+\left(2+\beta_{i}\right)(1-\right.$ $\left.\left.\beta_{-i}\right) c_{j}+\left(2+\beta_{-i}\right)\left(1-\beta_{i}\right) c_{-j}\right) \gamma^{2}+\left(1-\beta_{i}\right)\left(1-\beta_{-i}\right) \gamma^{4}$.

Using these results, we can check whether or not a non-monotonic relationship exists between $Q$ and $c_{j}$. To simplify the analysis, we now assume that $a_{D}=1, \beta_{D}=\beta_{F}=\beta$, and $c_{A}=c_{B}=c$. Then

$$
\begin{aligned}
\frac{\partial Q_{F, A}}{\partial c}= & -\frac{8(1+\beta)\left[\left(1+\beta+a_{F}\right)(2+\gamma)^{2}(4-\gamma+\beta \gamma)^{2}-8 a_{F} \beta(2+\beta)(2+\gamma)(4-\gamma+\beta \gamma) c\right]}{((2+\gamma)(4-\gamma+\beta \gamma)-4 \beta c)^{2}((2+\gamma)(4-\gamma+\beta \gamma)+4(2+\beta) c)^{2}} \\
& -\frac{8(1+\beta)\left[16 \beta(2+\beta)\left(1+\beta-a_{F}\right) c^{2}\right]}{((2+\gamma)(4-\gamma+\beta \gamma)-4 \beta c)^{2}((2+\gamma)(4-\gamma+\beta \gamma)+4(2+\beta) c)^{2}} .
\end{aligned}
$$

Since $Q_{i, j}>0$ for any $i, j$, the upper bound of $c$ is given by

$$
Q_{D, j}>0 \quad \Leftrightarrow \quad c<\frac{(2+\gamma)(4-\gamma+\beta \gamma)}{4\left((1+\beta) a_{F}-1\right)} \equiv \bar{c}_{d} .
$$

First note that $\partial Q_{F, A} / \partial c$ is negative when $c=0$. Next, we check whether there exists some range of $c$ such that $\partial Q_{F, A} / \partial c>0$. Substituting $c=\bar{c}_{d}$ into $\partial Q_{F, A} / \partial c$ to give

$$
\left.\frac{\partial Q_{F, A}}{\partial c}\right|_{c=\bar{c}_{d}}=\frac{8\left(1+\beta-a_{F}\right)\left(a_{F}-1+\beta a_{F}\right)}{\left(a_{F}^{2}-1\right)(1+\beta)(2+\gamma)^{2}(4-\gamma+\beta \gamma)} .
$$

From the calculation we have the following result.

Proposition 2 Suppose that $a_{D}=1, \beta_{D}=\beta_{F}=\beta$, and $c_{A}=c_{B}=c$. Then $Q_{F, j}$ is increasing in $c$ if $c_{F}<c<\bar{c}_{d}$ and $1<a_{F}<1+\beta$. 
Proposition 2 shows that the result in Proposition 1 is robust even when the number of manufacturers and retailers increase; that is, output (exports) can still fall when a firm's efficiency increases.

Note that for algebraic simplicity, we have assumed $c_{A}=c_{B}=c$. It is easy to find an example that an increase in heterogeneous $c_{i}(i=A, B)$ can increase the quantities supplied in market $F$. Also, if $a_{D}=a_{F}=1$, calculations give the following properties of $w_{i, j}$ and $Q_{i, j}$ :

$$
\frac{\partial w_{i, j}}{\partial c}>0, \quad \frac{\partial w_{i, j}}{\partial \beta_{i}}<0, \quad \frac{\partial w_{i, j}}{\partial \beta_{-i}}>0, \quad \frac{\partial Q_{i, j}}{\partial c}<0, \quad \frac{\partial Q_{i, j}}{\partial \beta_{i}}>0, \quad \frac{\partial Q_{i, j}}{\partial \beta_{-i}}<0 .
$$

\subsection{Downstream merger}

We are particularly interested in the case when the retailers in one market (say $F$ ) merge. Such a case is related to several prior researches (Naylor (2002), Lommerud et al. (2005), Matsushima (2006), Symeonidis (2010)), who explicitly or implicitly show that a merger between downstream duopolists does not always improve their profits when upstream suppliers have relatively strong bargaining power over downstream retailers, because the downstream merger eliminates the competition between the upstream suppliers, making them stronger to counter and offset the downstream merger.

In this subsection, we show that a downstream merger which leads to a monopoly does not improve the total profit of the merged entities if the bargaining power of the merged firm is strong, which is quite different from those in the literature.

For simplicity, we now assume $a_{D}=a_{F}=1$, i.e., the market size is the same for the two markets $D$ and $F$. Then the objective function of the merged firm is

$$
\pi_{F, M} \equiv\left(1-Q_{F, A}-\gamma Q_{F, B}-w_{F, A}\right) Q_{F, A}+\left(1-Q_{F, B}-\gamma Q_{F, A}-w_{F, B}\right) Q_{F, B}
$$

Profit maximization gives the first-order conditions as (Second order conditions are satisfied)

$$
Q_{F, j}=\frac{(1-\gamma)-2 w_{F, j}+\gamma w_{F,-j}}{2\left(1-\gamma^{2}\right)}, \quad \pi_{F, j}=\frac{\left(1-w_{F, j}\right) Q_{F, j}}{2}
$$

Similarly as before, we can obtain the first-order conditions for the negotiation between retailer $i, j$ 
and manufacturer $i$ as

$$
\begin{gathered}
w_{D, j}=\frac{1}{4\left(1-\gamma^{2}\right)\left(4-\gamma^{2}+2 c\right)} \times\left[(2-\gamma)(1-\gamma)\left(\left(1-\beta_{D}\right)\left(4-\gamma^{2}\right)(1+\gamma)+2\left(4+2 \beta_{D}+3 \gamma+\beta_{F} \gamma\right) c\right)\right. \\
\left.-2 c\left(1+\beta_{D}\right)\left(4-\gamma^{2}\right)\left(w_{F, j}-\gamma w_{F,-j}\right)+\left(1-\gamma^{2}\right) \gamma\left(\left(1-\beta_{D}\right)\left(4-\gamma^{2}\right)+4 c\right) w_{D,-j}\right] \\
w_{F, j}=\frac{1}{\left(4-\gamma^{2}\right)\left(2\left(1-\gamma^{2}\right)+c\right)} \times\left[(2-\gamma)(1-\gamma)\left(\left(1-\beta_{F}\right)\left(1-\gamma^{2}\right)(2+\gamma)+\left(4+2 \beta_{F}+3 \gamma+2 \beta_{D} \gamma\right) c\right)\right. \\
\left.-2 c\left(1+\beta_{F}\right)\left(1-\gamma^{2}\right)\left(2 w_{D, j}-\gamma w_{D,-j}\right)+\left(4-\gamma^{2}\right) \gamma\left(\left(1-\beta_{F}\right)\left(1-\gamma^{2}\right)+c\right) w_{F,-j}\right] .
\end{gathered}
$$

The basic properties of the reaction functions are similar to that in the non-merged case. That is,

Lemma 6 Suppose that $a_{D}=a_{F}=1$ and $c_{D}=c_{F}=c$. When the downstream retailers in market $F$ horizontally merge, in the reaction functions of $w_{D, j}$ and $w_{F, j}$, the coefficients of $w_{i,-j}, w_{-i, j}$, and $w_{-i,-j}$ are respectively positive, negative, and positive.

Using the reaction functions $w_{i, j}=w_{i, j}\left(w_{i,-j}, w_{-i, j}, w_{-i,-j}\right)$, we further obtain the following lemma: Lemma 7 Suppose that $a_{D}=a_{F}=1$ and $c_{D}=c_{F}=c$. When the downstream retailers in market $F$ horizontally merge, the equilibrium wholesale price $w_{i, j}$, the equilibrium quantity $Q_{i, j}$, the profit of each retailer, and the consumer surplus in each market are respectively

$$
\begin{aligned}
w_{D, j}= & \frac{\left(1-\beta_{D}\right)\left(4-\gamma^{2}\right)(1+\gamma)\left(2-\left(1-\beta_{F}\right) \gamma\right)}{H_{M}} \\
& +\frac{c\left(4\left(4+\beta_{F}\left(1+\beta_{D}\right)\right)+2\left(3+\beta_{D}\right)\left(1+\beta_{F}\right) \gamma-\left(5-\beta_{D}-4 \beta_{F}\right) \gamma^{2}\right)-4 c^{2}\left(\beta_{D}+\beta_{F}+\beta_{D} \beta_{F}\right)}{H_{M}}, \\
w_{F, j}= & \frac{\left(1-\beta_{F}\right)\left(1-\gamma^{2}\right)(2+\gamma)\left(4-\left(1-\beta_{D}\right) \gamma\right)}{H_{M}} \\
& +\frac{c\left(4\left(4+\beta_{D}\left(1+\beta_{F}\right)\right)+2\left(3+2 \beta_{F}\right)\left(1+\beta_{D}\right) \gamma-\left(5-\beta_{D}-4 \beta_{F}\right) \gamma^{2}\right)-4 c^{2}\left(\beta_{D}+\beta_{F}+\beta_{D} \beta_{F}\right)}{H_{M}}, \\
Q_{D, j}= & \frac{2\left(1+\beta_{D}\right)\left((1+\gamma)\left(2-\gamma+\beta_{F} \gamma\right)-\beta_{F} c\right)}{H_{M}}, \quad \pi_{D, j}=\left(Q_{D, j}\right)^{2}, \quad C S_{D}=(1+\gamma)\left(Q_{D, j}\right)^{2}, \\
Q_{F, j}= & \frac{\left(1+\beta_{F}\right)\left((2+\gamma)\left(4-\gamma+\beta_{D} \gamma\right)-4 \beta_{D} c\right)}{2 H_{M}}, \quad \pi_{F, M}=2(1+\gamma)\left(Q_{F, j}\right)^{2}, \quad C S_{F}=(1+\gamma)\left(Q_{F, j}\right)^{2} .
\end{aligned}
$$

where $H_{M} \equiv(1+\gamma)(2+\gamma)\left(2-\left(1-\beta_{F}\right) \gamma\right)\left(4-\left(1-\beta_{D}\right) \gamma\right)+c\left(16+2\left(3+\beta_{D}+2 \beta_{F}\right)-\left(5-\beta_{D}-4 \beta_{F}\right) \gamma^{2}\right)-$ $4 c^{2}\left(\beta_{D}+\beta_{F}+\beta_{D} \beta_{F}\right)$.

Also, calculations give the following properties of $w_{i, j}$ and $Q_{i, j}$ :

$$
\frac{\partial w_{i, j}}{\partial \beta_{i}}<0, \quad \frac{\partial w_{i, j}}{\partial \beta_{-i}}>0, \quad \frac{\partial Q_{i, j}}{\partial \beta_{i}}>0, \quad \frac{\partial Q_{i, j}}{\partial \beta_{-i}}<0, \text { for all exogenous parameters. }
$$


We now discuss the relation between $c$ and $w_{i, j}\left(Q_{i, j}\right)$. To simplify the exposition, we again assume $\beta_{D}=\beta_{F}=\beta$. For a large $c$, we have the following lemma:

Lemma 8 Suppoase that $\beta_{D}=\beta_{F}=\beta$. The wholesale price $w_{i, j}$ can be increasing in $c$.

Note that the details for this lemma can be shown as,

when $\beta \geq \frac{3 \gamma-2}{3 \gamma+2}, \quad \frac{\partial w_{F, j}}{\partial c}>0$ for all exogenous parameters and $\frac{\partial w_{D, j}}{\partial c}<0$

if and only if $c>\frac{2(2+\beta)(1+\gamma)(2-\gamma+\beta \gamma)}{2 \beta(2+\beta)}$

$$
-\frac{\sqrt{\gamma(1+\gamma)(1+\beta)(2+\beta)(2-\gamma+\beta \gamma)(2+2 \beta-3 \gamma+3 \beta \gamma)}}{2 \beta(2+\beta)} ;
$$

when $\beta \leq \frac{3 \gamma-2}{3 \gamma+2}, \quad \frac{\partial w_{D, j}}{\partial c}>0$ for all exogenous parameters and $\frac{\partial w_{F, j}}{\partial c}<0$

$$
\begin{aligned}
& \text { if and only if } c>\frac{(2+\beta)(2+\gamma)(4-\gamma+\beta \gamma)}{4 \beta(2+\beta)} \\
& \qquad-\frac{\sqrt{-\gamma(2+\gamma)(1+\beta)(2+\beta)(4-\gamma+\beta \gamma)(2+2 \beta-3 \gamma+3 \beta \gamma)}}{4 \beta(2+\beta)} .
\end{aligned}
$$

Therefore, if the bargaining power is strong and the cost parameter $c$ is large enough, an increase in $c$ can increase the quantities supplied by the retailers in market $D$, which again confirms the robustness of Proposition 1.

\subsection{The effect of downstream merger}

The merger is unprofitable if $\pi_{F, M}<2 \pi_{i, j}$, where $\pi_{i, j}$ and $\pi_{F, M}$ are given in (17) and (21). To simplify the exposition, we assume that $\beta_{D}=\beta_{F}=\beta$. Although calculation becomes more complicated, we can depict the difference between $\pi_{F, M}$ and $2 \pi_{i, j}, \Delta \pi_{F, j} \equiv \pi_{F, M}-2 \pi_{i, j}$ (see Figure 6 ). The figure leads to the following proposition:

Proposition 3 Suppose that $\beta_{D}=\beta_{F}=\beta$. An increase in either $\beta$ or c decreases $\Delta \pi_{F, j}$.

If the wholesale prices did not change, the merger would increase the profits of the merged retailer since downstream competition is removed. However, a counter-intuitive result arises here: the merger can increase the wholesale prices if the value of $c$ is large and the bargaining power of the retailer is high (see Lemma 8). The logic is as follows. The merger allows the merged retailers to change retail 
quantities flexibly, that is reflected in $Q_{i, j}$ in (15) and $Q_{F, j}$ in (19), the latter of which is more sensitive to $w_{F, j}$ than the former. This in turn affects the reaction function of $w_{D, j}$ (the wholesale price for the non-merged retailers). With the merger in market $i$, the reaction function of $w_{D_{j}}$ becomes more elastic with respect to $w_{F, j} \cdot{ }^{10}$ This arises since an increase in $w_{F, j}$ decreases $Q_{F, j}$ significantly, which relaxes the production 'capacity' of manufacturer $j$. Moreover, $Q_{i, j}$ monotonically increases in $\beta_{i}$. Therefore, if the bargaining power of retailers in market $i$ is strong, the merger in market $i$ allows retailers in market $-i$ to procure more inputs from the manufacturers. It in turn increases the marginal costs of the manufacturers, resulting in worse procurement conditions for the merged retailer and lowering its profits.

[Figure 6 here]

The merger also affects the threat points of the manufacturers. The decrease in the quantities supplied to the merged firm lowers the profits of the manufacturers, which also raises the non-merged retailer's bargaining position when negotiating with the manufacturer, lowering $w_{D, j}$. This then increases $w_{F, j}$, since the wholesale prices are strategic substitutes as shown earlier.

Finally, we briefly discuss the welfare implication of a downstream merger, using Figure 6 . When the bargaining power of the retailers is weak (small $\beta$ ), the downstream merger improves welfare, because the merger generates an outside value for the merged firm, which improves its procurement conditions. However, when $\beta$ is large, this positive effect is weak because the pre-merged downstream firms have already exerted their strong bargaining power. As in standard oligopoly theory, the elimination of the downstream competition between the merged entities worsens welfare.

\section{Conclusion}

This paper analyzed the relationship between a firm's productivity improvement and its volume of exports. Specifically, we simultaneously take into account intermediate traders (i.e., vertically) and

10 The difference between the coefficients of $w_{F, j}$ in the post-merger and the pre-merger is

$$
-\frac{2 c\left(1+\beta_{D}\right)\left(4-\gamma^{2}\right)}{4\left(1-\gamma^{2}\right)\left(4-\gamma^{2}+2 c\right)}-\left(-\frac{2 c\left(1+\beta_{D}\right)}{4-\gamma^{2}+2 c}\right)=-\frac{3 c\left(1+\beta_{D}\right) \gamma^{2}}{2\left(1-\gamma^{2}\right)\left(4-\gamma^{2}+2 c\right)}<0 .
$$

That is, the coefficients of $w_{F, j}$ in the post-merger is steeper that that in the pre-merger. 
multimarket linkages (i.e., horizontally) which have not been considered in the existing literature. We found that the manufacturer will adjust exports when facing productivity changes, by making corresponding changes in other related markets, to take advantage of its improved outside options. Our result might be a simple explanation to the interesting "productivity puzzle" posed by Ghemawat et al. (2010): there is "an apparent lack of any relationship" between productivity growth rates in Catalan manufacturing and changes in international trade position. It also highlights the importance of taking into account the vertical relationship between the manufacturer and retailers, as well as their strategic interactions through which profit shifting is carried out across multimarkets horizontally.

We also extended the model to examine the relationship between buyer power, profitability and social surplus. We find that the horizontal merger is unprofitable if the bargaining power of the merged firm is strong, but such a merger may improve welfare. Our result is quite different from those in the literature (Lommerud et al. (2005) and Symeonidis (2010)) which show that the horizontal merger is unprofitable if the bargaining power of the upstream supplier is strong. 


\section{Appendix}

Here we show that Lemma 1 holds under general cost and demand conditions. We add the following notation: $\pi_{D}\left(w_{D}\right)$ is the profit of the domestic retailer with $\pi_{D}^{\prime}\left(w_{D}\right)<0, Q_{D}\left(w_{D}\right)$ is the demand in the domestic market $\left(Q_{D}^{\prime}\left(w_{D}\right)<0\right), Q_{F}\left(w_{F}\right)$ is the demand in the foreign market $\left(Q_{F}^{\prime}\left(w_{F}\right)<0\right)$, and $c(\cdot)$ is the cost function of the manufacturer $\left(c^{\prime}>0, c^{\prime \prime}>0\right)$.

The bargaining problem between $M$ and $D$ is

$$
\begin{aligned}
& \operatorname{Max} \beta \log \left[\pi_{D}\left(w_{D}\right)\right] \\
& +(1-\beta) \log \left[w_{D} Q_{D}\left(w_{D}\right)+w_{F} Q_{F}\left(w_{F}\right)\right. \\
& \left.\quad-c\left(Q_{D}\left(w_{D}\right)+Q_{F}\left(w_{F}\right)\right)-\left\{w_{F} Q_{F}\left(w_{F}\right)-c\left(Q_{F}\left(w_{F}\right)\right)\right\}\right] \\
& \Rightarrow \beta \log \left[\pi_{D}\left(w_{D}\right)\right]+(1-\beta) \log \left[w_{D} Q_{D}\left(w_{D}\right)-c\left(Q_{D}\left(w_{D}\right)+Q_{F}\left(w_{F}\right)\right)+c\left(Q_{F}\left(w_{F}\right)\right)\right],
\end{aligned}
$$

which leads to the first-order condition

$$
\beta \frac{\pi_{D}^{\prime}\left(w_{D}\right)}{\pi_{D}\left(w_{D}\right)}+(1-\beta) \frac{w_{D} Q_{D}^{\prime}\left(w_{D}\right)+Q_{D}\left(w_{D}\right)-c^{\prime}\left(Q_{D}\left(w_{D}\right)+Q_{F}\left(w_{F}\right)\right) Q_{D}^{\prime}\left(w_{D}\right)}{w_{D} Q_{D}\left(w_{D}\right)-c\left(Q_{D}\left(w_{D}\right)+Q_{F}\left(w_{F}\right)\right)+c\left(Q_{F}\left(w_{F}\right)\right)}=0
$$

The numerator of the second fraction, $w_{D} Q_{D}^{\prime}\left(w_{D}\right)+Q_{D}\left(w_{D}\right)-c^{\prime}\left(Q_{D}\left(w_{D}\right)+Q_{F}\left(w_{F}\right)\right) Q_{D}^{\prime}\left(w_{D}\right)$, must be positive because the denominators of the fractions are positive and $\pi_{D}^{\prime}\left(w_{D}\right)<0$.

The total differential of the first-order condition is

$$
\begin{aligned}
\text { (S.O.C. }) d w_{D}+(1-\beta)\left[\frac{-c^{\prime \prime}\left(Q_{D}+Q_{F}\right) Q_{F}^{\prime} Q_{D}^{\prime}\left[w_{D} Q_{D}-c\left(Q_{D}+Q_{F}\right)+c\left(Q_{F}\right)\right]}{\left[w_{D} Q_{D}-c\left(Q_{D}+Q_{F}\right)+c\left(Q_{F}\right)\right]^{2}}\right. & \\
& \left.+\frac{\left(c^{\prime}\left(Q_{D}+Q_{F}\right)-c^{\prime}\left(Q_{F}\right)\right) Q_{F}^{\prime}\left[w_{D} Q_{D}^{\prime}+Q_{D}-c^{\prime}\left(Q_{D}+Q_{F}\right) Q_{D}^{\prime}\right]}{\left[w_{D} Q_{D}-c\left(Q_{D}+Q_{F}\right)+c\left(Q_{F}\right)\right]^{2}}\right] d w_{F}=0 .
\end{aligned}
$$

Both the first and second fractions are negative $\left(c^{\prime \prime}\left(Q_{D}+Q_{F}\right)>0, Q_{D}^{\prime}<0, Q_{F}^{\prime}<0, w_{D} Q_{D}-c\left(Q_{D}+\right.\right.$ $\left.\left.Q_{F}\right)+c\left(Q_{F}\right)>0\right)$, and $\left(c^{\prime}\left(Q_{D}+Q_{F}\right)-c^{\prime}\left(Q_{F}\right)>0, Q_{F}^{\prime}<0, w_{D} Q_{D}^{\prime}+Q_{D}-c^{\prime}\left(Q_{D}+Q_{F}\right) Q_{D}^{\prime}>0\right)$. Thus the coefficient of $d w_{F}$ is negative. Since the second order condition is also negative, we have $d w_{D} / d w_{F}<0$, which means that the prices charged to retailers are strategic substitutes under general conditions. 


\section{References}

[1] Bernard, Andrew B., Eaton, Jonathan, Jensen, J. Bradford, And Kortum, Samuel, 2003. "Plants and productivity in international trade," American Economic Review, 93(4), 1268-90.

[2] Bernard, Andrew B. And Jensen, J. Bradford, 1995. "Exporters, jobs, and wages in U.S. manufacturing: 1976-1987," Brookings Papers on Economic Activity: Microeconomics, 67-119.

[3] Bernard, Andrew B. And Jensen, J. Bradford, 1999. "Exceptional exporter performance: cause, effect, or both?," Journal of International Economics, 47(1), 1-25.

[4] Binmore, Ken, Rubinstein, Ariel, And Wolinsky, Asher, 1986. "The Nash bargaining solution in economic modelling," RAND Journal of Economics, 17(2), 176-188.

[5] Chen, Zhiqi 2003. "Retailers and the countervailing-power hypothesis," RAND Journal of Economics, 34(4), 612-625.

[6] Dobson, Paul W., 1994. "Multifirm unions and the incentive to adopt pattern bargaining in oligopoly," European Economic Review, 38(1), 87-100.

[7] Eső, PÉter, Nocke, Volker, And White, Lucy, 2010. "Competition for scarce resources," RAND Journal of Economics, 41(3), 524-548.

[8] Ghemawat, Pankaj, Llano, Carlos, and Requena, Francisco, 2010. "Competitiveness and interregional as well as international trade: The case of Catalonia," International Journal of Industrial Organization, 28(4), 415-422.

[9] Helpman, Elhanan, Melitz, Marc J., and Yeaple, Stephen R., 2004. "Export versus FDI with heterogeneous firms," American Economic Review, 94(1), 300-16.

[10] Horn, Henrick And Wolinsky, Asher, 1988. "Bilateral monopolies and incentives for merger," RAND Journal of Economics, 19(3), 408-419.

[11] InDERST, Roman 2010. "Models of vertical market relations," International Journal of Industrial Organization, 28(4), 341-344. 
[12] Inderst, Roman and Shaffer, Greg 2007. "Retail mergers, buyer power and product variety," Economic Journal, 117(516), 45-67.

[13] Inderst, Roman and Valletti, Tommaso M. 2009. "Buyer power and the "Waterbed Effect"" Journal of Industrial Economics, forthcoming.

[14] Inderst, Roman and Wey, Christian 2007. "Buyer power and supplier incentives" European Economic Review, 51(3), 647-667.

[15] Iyer, Ganesh and Villas-Boas, J. Miguel, 2003. "A bargaining theory of distribution channels," Journal of Marketing Research, 40(1), 80-100.

[16] Lommerud, KJell Erik, Straume, Odd Rune, and Sørgard, Lars 2005. "Downstream merger with upstream market power," European Economic Review, 49(3), 717-743.

[17] Marshall, Robert C. and Merlo, Antonio, 2004. "Pattern bargaining," International Economic Review, 45(1), 239-255.

[18] Matsushima, Noriaki, 2006. "Industry profits and free entry in input markets," Economics Letters 93(3), 329-336.

[19] Melitz, Marc J., 2003. "The impact of trade on intra-industry reallocations and aggregate industry productivity," Econometrica 71(6), 1695-1725.

[20] Melitz, Marc J., and Ottaviano, Gianmarco I.P., 2008. "Market size, trade, and productivity," Review of Economic Studies 75(1), 295-316.

[21] NAYLOR, Robin A., 2002. "Industry profits and competition under bilateral oligopoly," Economics Letters $\mathbf{7 7}(2), 169-175$.

[22] Rey, Patrick and Tirole, Jean, 2007. "A primer on foreclosure," Eds. M. Armstrong, M., Porter, R. eds. Handbook of Industrial Organization Vol. 3, 2145-2220, North-Holland.

[23] Rubinstein, Ariel 1982. "Perfect equilibrium in a bargaining model," Econometrica 50(1), 97109. 
[24] Symeonidis, George 2010. "Downstream marger abd welfare in a bilateral oligopoly," International Journal of Industrial Organization, 28(2), 230-234.

[25] Wagner, Joachim, 2007. "Exports and productivity: a survey of the evidence from firm-level data," The World Economy 30(1), 60-82.

[26] ZhaO, Laixun, 2001. "Unionization, Vertical Markets, and the Outsourcing of Multinationals," Journal of International Economics 55(1), 187-202. 


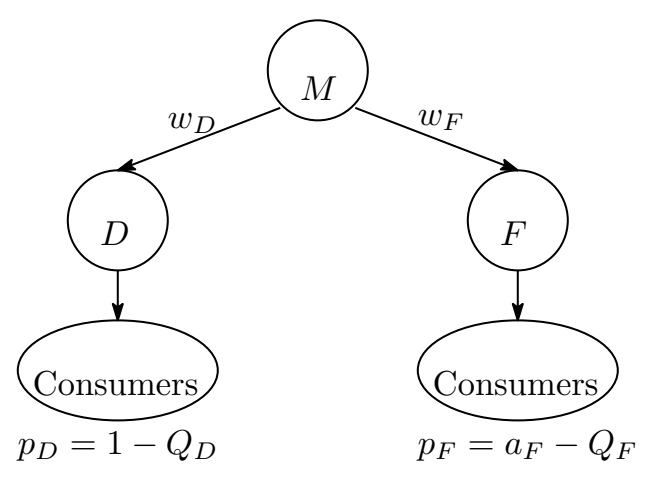

Figure 1: The market structure 


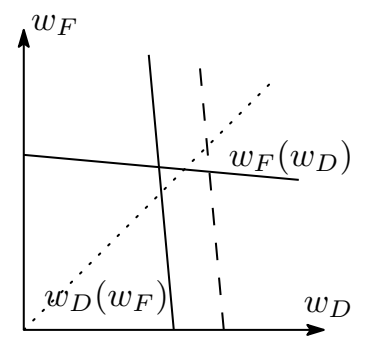

$c$ is small.

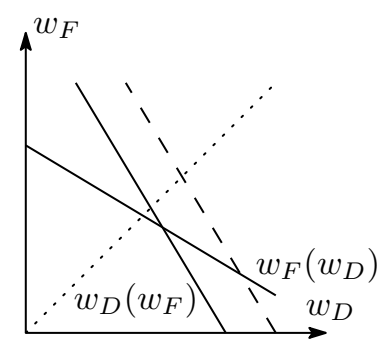

$c$ is large.

Figure 2: The reaction functions 

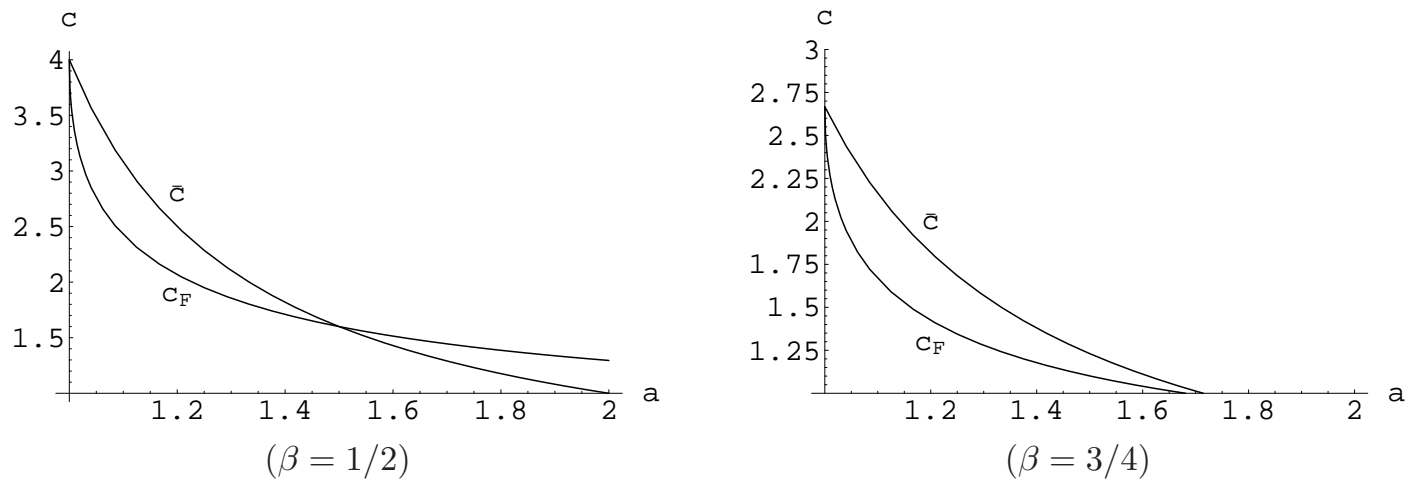

Figure 3: The condition that $\partial Q_{F} / \partial c>0$. 

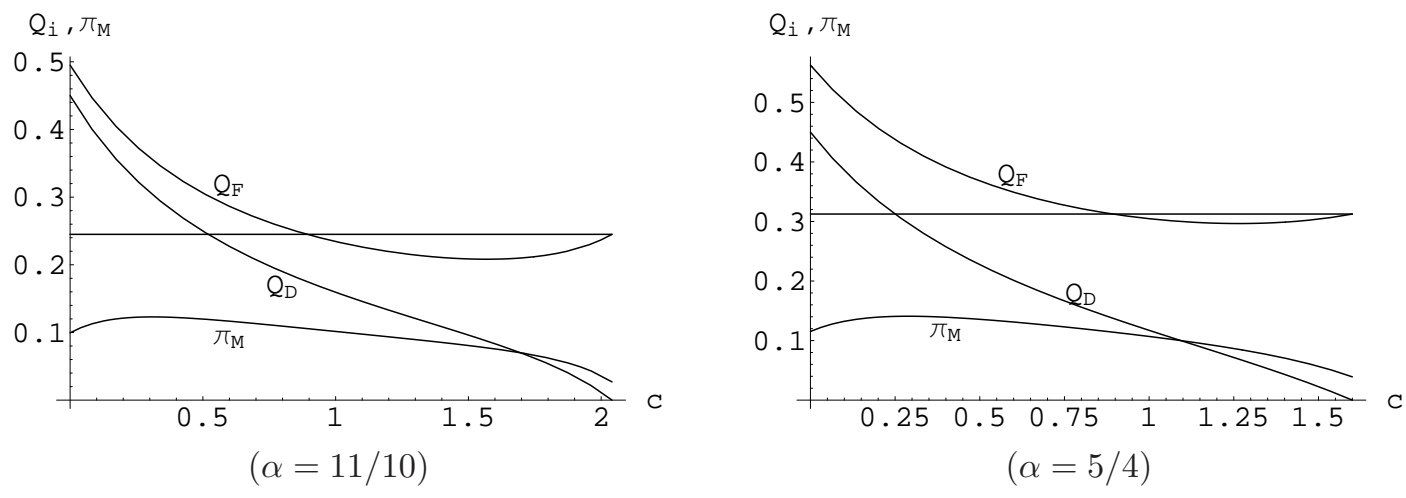

Figure 4: The relation between $c$ and $Q_{D}, Q_{F}$, and $\pi_{M}$. 


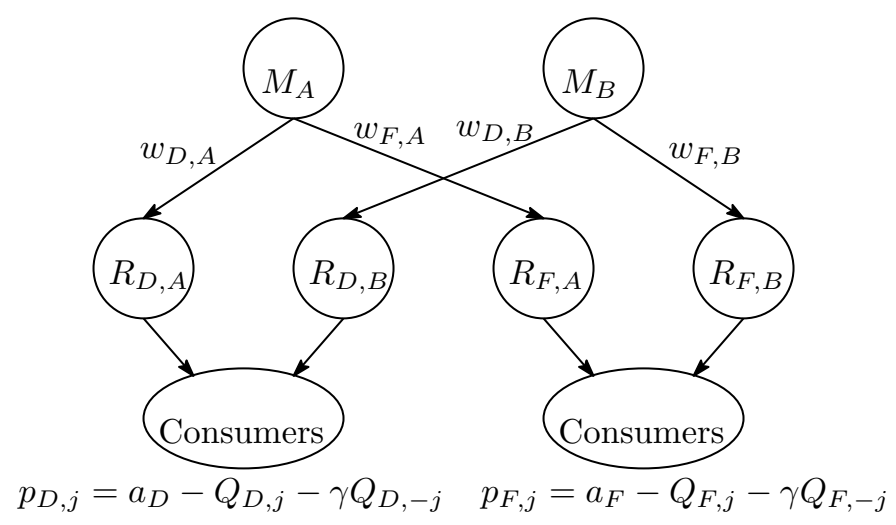

Figure 5: The market structure 


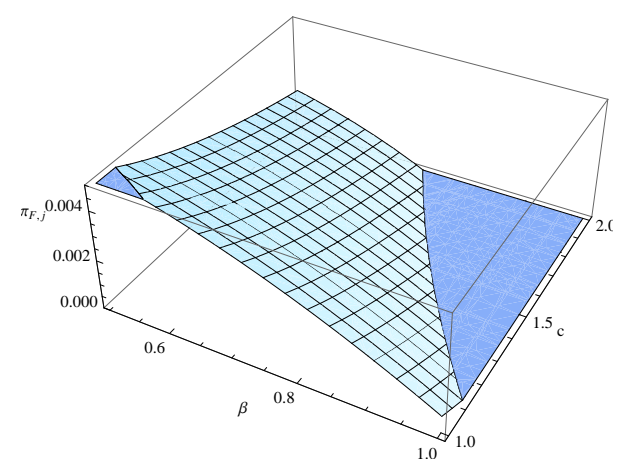

$\Delta \pi_{F, j}$

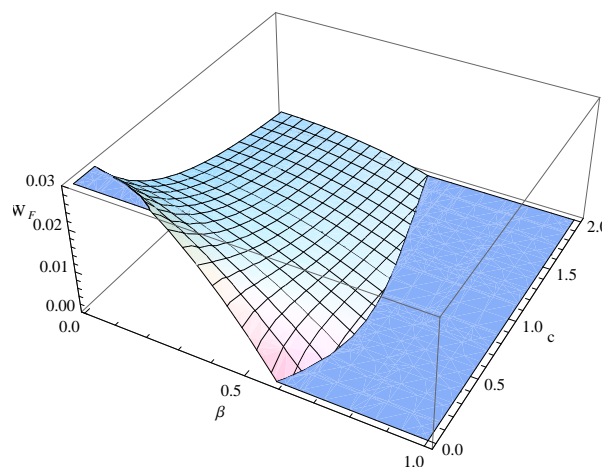

$\Delta S W_{F, j}$

Figure 6: The values of $\Delta \pi_{F, j}$ and $\Delta S W_{F, j}(\gamma=1 / 2)$. 